Acta Theriologica 42 (1): 91-98, 1997.

PL ISSN 0001-7051

\title{
Internal organ masses of the red fox Vulpes vulpes: data from the wild
}

\author{
Paolo CAVALLINI
}

\begin{abstract}
Cavallini P. 1997. Internal organ masses of the red fox Vulpes vulpes: data from the wild. Acta Theriologica 42: 91-98.

Totally, 330 (125 females, 205 males) red foxes Vulpes vulpes (Linnaeus, 1758), killed during predator control operations (January to April 1992) in central Italy, were dissected. Their kidneys, spleen, heart, liver, and adrenal glands were weighed and related to body mass, age, sex, and kidney fat index. The mass of all organs examined, except for the adrenal glands, was highly correlated with body mass. Sex, age, and fat did not affect liver or spleen mass. Kidney fat was negatively related to the mass of heart and kidneys. Only kidneys and adrenals increased in mass with age. The increases were small, and could not explain an increase of total body mass with age. The hearts and spleens were relatively heavier in wild foxes than in farmed foxes, whereas livers were relatively lighter. Environmental factors (exposure to parasites and physical activity) may explain the differences. The masses of all of the organs were more variable in wild foxes than in farmed foxes, possibly because of a greater environmental and genetic variability.
\end{abstract}

University of Florence, Department of Animal Biology and Genetics, via Romana 17/19, 50125 Florence, Italy; e-mail: cavallini@unisi.it

Key words: Vulpes vulpes, internal organ masses, environmental factors

\section{Introduction}

The red fox Vulpes vulpes (Linnaeus, 1758) has one of the widest distributions of terrestrial mammals (excluding man and commensal species; eg Lloyd 1980, Henry 1986). It is also farmed for fur (Ginsberg and Macdonald 1990). The fox is one of the most studied carnivores in Europe (eg Zimen 1980) and in North America (eg Ables 1975). Its external morphology has been studied in a variety of areas from Norway to Australia (Lund 1959, McIntosh 1963), but its internal morphology has largely been ignored except for a small sample of farmed animals (Zhan et al. 1991). Data from the wild are lacking. A continuous slow growth of various organs has been hypothesized as a cause of body mass increase with age (Allen and Gulke 1981), but no data support this view.

The aims of this paper are to provide reference data on the mass of kidneys, spleen, heart, liver, and adrenal glands of wild foxes, to evaluate differences related to body mass, sex, age, and body condition, and to compare the results with data from a captive group (Zhan et al. 1991). 


\section{Material and methods}

Foxes used for the present study were killed between January and April 1992 in the Province of Pisa $\left(43^{\circ} \mathrm{N}, 10-11^{\circ} \mathrm{E}\right)$, central Italy, during predator control operations. The area $(52 \mathrm{~km} \mathrm{E}-\mathrm{W}$ by 75 $\mathrm{km} \mathrm{N}-\mathrm{S}, 2448 \mathrm{~km}^{2}$ ) is mostly flat and intensively cultivated (mainly cereals) in the north, becoming increasingly hilly (up to $800 \mathrm{~m}$ a.s.l.) and wooded towards the south. Climate is Mediterranean, with mild winters and dry, hot summers. Foxes were collected from hunters within 6 hours from death and kept in plastic bags in a refrigerator cell ( $\leq 48$ hours, $\left.-2^{\circ} \mathrm{C}\right)$ until weighing $( \pm 50 \mathrm{~g})$ and dissection. Totally, 330 foxes (125 females, 205 males) was collected. Because of physical damage during hunting, sample size for all the variables was variously reduced (from 264 to 198; Table 1). For details on body measurement, see Cavallini (1995). The kidneys, spleen, heart, liver, and adrenal glands were excised (with attachments removed), cleaned of any excess blood, and weighed to the nearest mg. Damaged samples were excluded. Age was determined by counting the cementum annuli of decalcified and stained canine teeth, by measuring canine teeth pulpar width, and by weighing eye lenses, with good accordance among methods (Cavallini and Santini 1995). Body conditions were evaluated by the logarithm of the kidney fat index (hereafter KFI; LaJeunesse and Peterson 1993, Cavallini 1996). Gut contents were measured, but they represented an average of only $2.7 \%$ of body mass (Cavallini 1995, Cavallini and Volpi 1996) and did not explain a significant proportion of variation in body mass (Cavallini 1996). They were therefore not taken in account in the present analysis.

\section{Statistical analyses}

Normality of data distribution was assessed by the Lilliefors test (a modified Kolmogorov-Smirnov one-sample test; Lilliefors 1967). Figures are reported as the mean \pm 1 standard deviation. Parametric statistics were employed for variables normally distributed, and non-parametric statistics (when available) for others. The effects of body mass, sex, age, and body condition on the mass of each organ or gland were evaluated by the multivariate general linear hypothesis (MGLH; Wilkinson 1990). For non-normal variables, the results of MGLH were confirmed by univariate non-parametric statistics. Because of the small number of older foxes (Cavallini and Santini 1995; and Fig. 1) the effect of age (in years; pooling ages $\geq 4$ years) was tested only when the effect of age class (young: $\leq 1$ year, adults: $>1$ year) was significant. Regression residuals wer e examined to test assumptions of the linear model (normality, constant variance, and independence of errors; linearity of relations; Wilkinson 1990).

\section{Results}

Mass of most organs was normally distributed (liver: $\mathrm{D}=0.084, p=0.121$; heart: $\mathrm{D}=0.074, p=0.228$; L kidney: $\mathrm{D}=0.074, p=0.111$; $\mathrm{R}$ kidney: $\mathrm{D}=0.088$, $p=0.057$ ). The distributions of spleen and of both adrenal masses were significantly different from normality (spleen: $\mathrm{D}=0.139, p=0.001$; $\mathrm{L}$ adrenal: $\mathrm{D}=0.131$, $p<0.001$; $\mathrm{R}$ adrenal: $\mathrm{D}=0.109, p=0.017)$. Males weighed $5750 \pm 953 \mathrm{~g}$; females were lighter, $4940 \pm 680 \mathrm{~g}$ (see Cavallini 1995).

Average mass of the left kidney was greater than that of the right kidney (average difference $=0.24 \pm 1.13 \mathrm{~g}, t=4.308, p<0.0001, n=215$ ); also the left adrenals were larger than right adrenals (Wilcoxon signed rank test: $Z=3.33$, $p=0.0009, n=157$; Table 1). Left and right organs were therefore analysed 
Table 1. Descriptive statistics for the mass (in g) of internal organs of red foxes collected in the Pisa province, central Italy (January-April 1992). CV - coefficient of variation, L left, $\mathrm{R}$ - right.

\begin{tabular}{lrrrrrr}
\hline & Mean & SD & Minimum & Maximum & CV \% & $n$ \\
\hline Liver & 126.20 & 28.54 & 70.14 & 222.68 & 22.6 & 198 \\
Heart & 52.40 & 10.54 & 27.91 & 83.96 & 20.1 & 199 \\
Spleen & 17.06 & 5.54 & 8.87 & 46.38 & 32.5 & 205 \\
L Kidney & 15.59 & 3.33 & 8.96 & 26.02 & 21.4 & 264 \\
R Kidney & 15.35 & 3.45 & 8.76 & 25.03 & 22.5 & 227 \\
L Adrenal & 0.262 & 0.075 & 0.090 & 0.560 & 28.5 & 244 \\
R Adrenal & 0.260 & 0.075 & 0.110 & 0.580 & 28.8 & 200 \\
\hline
\end{tabular}

separately. Both range and coefficient of variation were large for all organs; CV was the largest for spleen (32.5\%) and the smallest for the heart $(20.1 \%$; Table 1$)$.

Body mass had a strong positive and linear effect on the mass of all organs except for the adrenals (Table 2). The effect was estimated to be similar for the kidneys and for the spleen (an increase of about $2 \mathrm{~g}$ for each additional $\mathrm{kg}$ of body mass), larger for the heart $(6 \mathrm{~g} / \mathrm{kg})$, and largest for the liver $(14 \mathrm{~g} / \mathrm{kg})$. When the effect of body mass was removed, none of the other variables had any effect on liver or spleen mass. Only the kidney fat index was weakly and negatively related to heart mass. By contrast, all four variables were related to the mass of both kidneys. Males had heavier kidneys than females, and adults heavier than young. The increase with age was continuous (univariate ANOVA, pooling ages $\geq 4$ years; L kidney: $F=4.65, p=0.004, n=257$; R kidney: $F=4.46, p=0.005, n=220$; Fig. 1). Foxes with higher kidney fat index had lighter kidneys (especially the left). Mass of both adrenals increased with age class, whereas sex affects the right adrenal only, and KFI was related to left adrenal mass only (Table 2).

Because of the non-normality in the distribution of spleen and adrenal masses, and because the corresponding coefficients of determination were the smallest $\left(R^{2} \leq 0.153\right.$; Table 2$)$, the results of multivariate analyses were confirmed by use of univariate, non-parametric analyses for the spleen and adrenals. This approach showed that the mass of both adrenals increased significantly with age (Kruskal-Wallis one-way ANOVA: L adrenal: $H=26.1, p=0.0005, n=237$; $\mathrm{R}$ adrenal: $H=20.3, p=0.005, n=194$; Fig. 1 ). The correlation between body mass and spleen mass was highly significant (Spearman rank correlation, $r_{\mathrm{S}}=0.419, p<$ $0.0001, n=204)$. Other relations were not significant.

During the period of study, there was no significant variation of mass with time for both kidneys, for adrenals and for the spleen (all $R^{2}<0.012, p>0.08$, $n>200$ ). The heart and liver masses, however, decreased significantly (heart: $R^{2}=0.036, p=0.007, n>199,-0.114$ g/day; liver: $R^{2}=0.052, p=0.001, n>198$, $-0.368 \mathrm{~g} /$ day). 
Table 2. Multivariate effects of body mass, kidney fat index (KFI), sex, and age class ( $\leq 1$ years vs $>1$ year) on the mass of selected internal organs of wild red foxes (coefficients of determination are: liver: $R^{2}=0.286$, constant $=58.29, n=184$; heart: $R^{2}=0.397$, constant = 23.76, $n=185$; spleen: $R^{2}=0.128$, constant $=7.33, n=192$; L kidney: $R^{2}=0.519$, constant $=6.95, n=252$; $\mathrm{R}$ kidney: $R^{2}=0.553$, constant $=5.43, n=215 ; \mathrm{L}$ adrenal: $R^{2}=$ 0.137 , constant $=0.248, n=233$; $\mathrm{R}$ adrenal: $R^{2}=0.153$, constant $\left.=0.227, n=188\right)$. ${ }^{*}-$ variables non-normally distributed (results should be taken with caution; see text).

\begin{tabular}{|c|c|c|c|}
\hline Source & $F$-ratio & $p$ & Estimated effect \\
\hline \multicolumn{4}{|l|}{ Liver } \\
\hline Body mass & 41.758 & $<0.0001$ & $13.69 \mathrm{~g} / \mathrm{kg}$ \\
\hline KFI & 1.362 & 0.245 & - \\
\hline Sex & 1.897 & 0.170 & - \\
\hline Age class & 1.716 & 0.192 & - \\
\hline \multicolumn{4}{|l|}{ Heart } \\
\hline Body mass & 66.710 & $<0.0001$ & $5.94 \mathrm{~g} / \mathrm{kg}$ \\
\hline $\mathrm{KFI}$ & 5.054 & 0.026 & $-9.93 \mathrm{~g}$ \\
\hline Sex & 2.511 & 0.115 & - \\
\hline Age class & 0.004 & 0.952 & - \\
\hline \multicolumn{4}{|l|}{ Spleen* } \\
\hline Body mass & 18.678 & $<0.0001$ & $1.93 \mathrm{~g} / \mathrm{kg}$ \\
\hline KFI & 0.370 & 0.544 & - \\
\hline Sex & 0.212 & 0.646 & - \\
\hline Age class & 0.213 & 0.645 & - \\
\hline \multicolumn{4}{|l|}{ L kidney } \\
\hline Body mass & 126.353 & $<0.0001$ & $1.92 \mathrm{~g} / \mathrm{kg}$ \\
\hline KFI & 22.671 & $<0.0001$ & $-4.86 \mathrm{~g}$ \\
\hline Sex & 9.139 & 0.003 & Males: $+0.54 \mathrm{~g}$ \\
\hline Age class & 11.048 & 0.001 & Adults: $+0.50 \mathrm{~g}$ \\
\hline \multicolumn{4}{|l|}{ R kidney } \\
\hline Body mass & 122.874 & $<0.0001$ & $2.01 \mathrm{~g} / \mathrm{kg}$ \\
\hline KFI & 6.945 & 0.009 & $-2.88 \mathrm{~g}$ \\
\hline Sex & 15.132 & 0.0001 & Males: $+0.76 \mathrm{~g}$ \\
\hline Age class & 9.831 & 0.002 & Adults: $+0.51 \mathrm{~g}$ \\
\hline \multicolumn{4}{|l|}{ L adrenal* } \\
\hline Body mass & 1.952 & 0.164 & - \\
\hline KFI & 5.315 & 0.022 & - \\
\hline Sex & 3.511 & 0.062 & - \\
\hline Age class & 12.278 & 0.0006 & Adults: $+0.016 \mathrm{~g}$ \\
\hline \multicolumn{4}{|l|}{$\mathrm{R}$ adrenal* } \\
\hline Body mass & 1.743 & 0.188 & - \\
\hline KFI & 0.778 & 0.379 & - \\
\hline Sex & 9.123 & 0.003 & - \\
\hline Age class & 9.895 & 0.002 & Adults: $+0.016 \mathrm{~g}$ \\
\hline
\end{tabular}



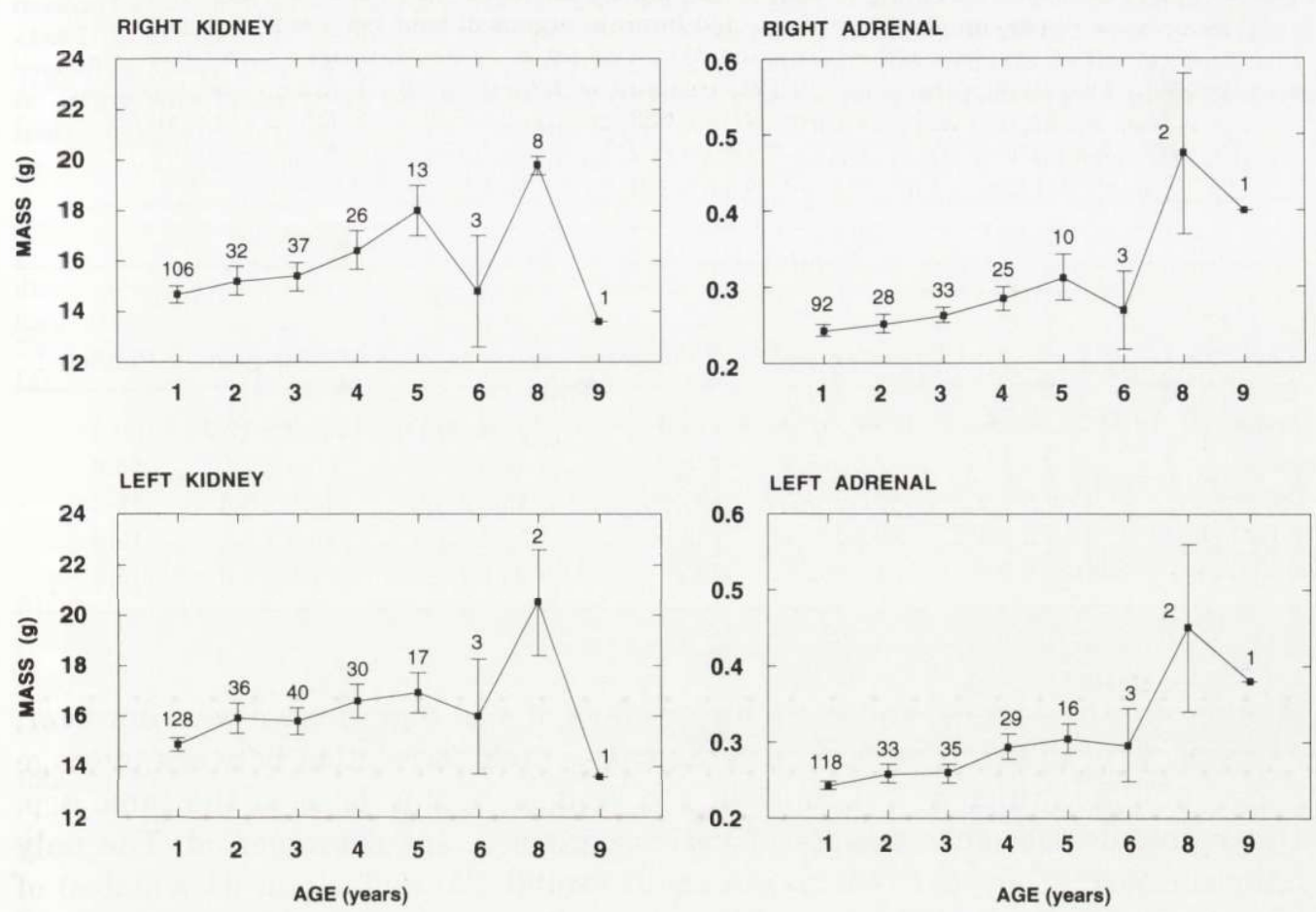

Fig. 1. Increase of the mass of the left and right kidneys and left and right adrenal glands of wild red foxes from central Italy with age. Mean, standard error and sample sizes for each age are shown.

\section{Discussion}

Body mass is the single most important factor positively related to the mass of the internal organs examined in this investigation. The only exceptions were the adrenals which may be more related to other factors (eg amount of stress; Baxter and Tyrrell 1987). Fatter foxes had lighter heart and kidneys. Only the kidneys and adrenals increase with age, and their increases are small (about $1 \mathrm{~g}$ each per year). Thus, increase in body mass with age cannot be attributed to the growth of the larger internal organs (in contrast to the hypothesis of Allen and Gulke 1981). In the Pisa Province, however, body mass increase with age was not significant for either sex (Cavallini 1995).

To the best of the author's knowledge, no previous data are available on the mass of the organs reported here for wild red foxes. Significant age-related differences in the mass of heart, adrenal, and kidney have been reported by Nelson and Chapman (1982) for wild foxes in Maryland. Because organ mass was related to body mass, this result is probably related to the significantly greater body mass 
Table 3. Comparison of the mass (in g) of selected organs between wild foxes from Italy (present study) and foxes farmed in Japan (25 females and 20 males; observed values from Zhan et al. 1991). Predicted values are calculated by multiplying the average mass difference between wild and farmed foxes ( $2950 \mathrm{~g}$ for males, $1160 \mathrm{~g}$ for females) by the effect of body mass on mass of each organ, as estimated from the Italian sample (see Table 2). Plus and minus signs (+/-) indicate predicted values much larger or smaller (> $1 \mathrm{SD}$ ), respectively, than those observed for Japanese foxes.

\begin{tabular}{|c|c|c|c|c|c|c|}
\hline & \multicolumn{3}{|c|}{ Males } & \multicolumn{3}{|c|}{ Females } \\
\hline & \multirow[t]{2}{*}{ Italy } & \multicolumn{2}{|c|}{ Japan } & \multirow[t]{2}{*}{ Italy } & \multicolumn{2}{|c|}{ Japan } \\
\hline & & Observed & Predicted & & Observed & Predicted \\
\hline Liver & $133.8 \pm 28.4$ & $189.0 \pm 20.6$ & 174.8 & $114.2 \pm 24.5$ & $165.2 \pm 17.0$ & $130.3-$ \\
\hline Heart & $55.9 \pm 10.7$ & $57.6 \pm 5.3$ & $73.4+$ & $47.0 \pm 7.7$ & $50.4 \pm 7.9$ & 53.9 \\
\hline Spleen & $17.9 \pm 5.8$ & $13.5 \pm 6.4$ & $23.6+$ & $15.8 \pm 4.8$ & $12.0 \pm 5.4$ & $18.3+$ \\
\hline L kidney & $16.9 \pm 3.4$ & $20.9 \pm 2.4$ & 22.6 & $13.7 \pm 2.2$ & $16.8 \pm 3.4$ & 15.9 \\
\hline R kidney & $16.8 \pm 3.4$ & $21.2 \pm 2.2$ & 22.7 & $13.2 \pm 2.1$ & $17.0 \pm 2.6$ & 15.5 \\
\hline
\end{tabular}

of adults in the sample, and not a direct effect of age. Significance was, however, assessed with incorrect statistical techniques (rank correlation between average mass and age), which do not consider the variance within foxes of the same age. Unfortunately, absolute masses of various organs were not reported. The only comparable data are derived from a small sample (20 males and 25 females) of silver foxes (Vulpes vulpes) farmed in Japan (Zhan et al. 1991). Those foxes were heavier (males: $8.7 \pm 1.0 \mathrm{~kg}$, females: $6.1 \pm 1.1 \mathrm{~kg}$ ), and their kidneys were proportionally heavier (ie they were close to the values expected from the relationship 'body mass vs organ mass' found for the Italian wild foxes; Table 3). The spleen of farmed foxes was both relatively and absolutely lighter, whereas the heart (especially of males) was relatively lighter, and the liver (especially of females) was relatively heavier (Table 3 ). Environmental differences may explain the observed trend: in the wild, foxes are more active (which may explain heavier hearts) and are exposed to a wide array of parasites and diseases (eg Borgsteede 1984, Poli et al. 1984, Cavallini 1994), which may invoke a strong immune reaction resulting in an enlargement of the spleen. Alternatively, genetic differences due to selection in captivity might underlie the observed differences. The coefficient of variation for all organs was substantially larger in my sample (20-33\%) than in farmed foxes (mostly $\leq 20 \%$; Zhan et al. 1991), possibly because of greater environmental and genetic uniformity within the farmed population. In both instances, however, spleen mass shows a large individual variation, which may be related to individual differences in parasitological status. Adrenals of wild foxes from central Italy (males: $0.236 \pm 0.080 \mathrm{~g}$, females: $0.276 \pm 0.065 \mathrm{~g}$ ) are much lighter than those from Indiana, USA (males: $0.557 \pm 0.057 \mathrm{~g}$; females: $0.447 \pm$ $0.019 \mathrm{~g}$; Hoffman and Kirkpatrick 1954), whereas they are probably more similar to those of foxes from Maryland (range: $0.045-0.500 \mathrm{~g}$; Nelson and Chapman 1982), 
although the average for Maryland foxes is unknown. The trend of heavier adrenals in warmer climates, found within a small area (Nelson and Chapman 1982) might be confirmed also on a larger, geographical scale. Further studies on foxes from other areas are needed to verify the influence of genetic and environmental factors on the mass of internal organs.

Acknowledgments: Funding for this study has been provided by the Amministrazione Provinciale di Pisa (M. Franceschini). S. Santini, T. Volpi, Prof A. Poli and his staff greatly helped during dissections. The guidance and support of the late Prof R. Nobili, Prof S. Lovari and Prof R. Dallai made this study possible. The collaboration of hunters and game wardens is gratefully acknowledged. The Museum of Natural History of the University of Pisa and the Museum of Natural History of Livorno kindly provided logistic support.

\section{References}

Ables E. D. 1975. Ecology of the red fox in North America. [In: The wild canids. Their systematics, behavioral ecology and evolution. M. W. Fox, ed]. Van Nostrand Reinhold Co., New York: $216-236$.

Allen S. H. and Gulke J. 1981. The effect of age on adult red fox body weights. The Prairie Naturalist 13: $97-98$.

Baxter J. D. and Tyrrell J. B. 1987. The adrenal cortex. [In: Endocrinology and metabolism. P. Felig, J. D. Baxter, A. E. Broadus and L. A. Frohman, eds]. McGraw-Hill, New York: 511-650.

Borgsteede F. H. M. 1984. Helminth parasites of wild foxes (Vulpes vulpes L.) in the Netherlands. Zeitschrift für Parasitenkunde 70: 281-285.

Cavallini P. 1994. Variations in the biology of the red fox Vulpes vulpes (Linnaeus). Ph D thesis, University of Siena, Italy: 1-120. [In Italian]

Cavallini P. 1995. Variation in the body size of the red fox. Annales Zoologici Fennici 32: 421-427.

Cavallini P. 1996. Comparison of body condition indices in the red fox (Fissipedia, Canidae). Mammalia 60: 449-462.

Cavallini P. and Santini S. 1995. Age determination in the red fox in a Mediterranean habitat. Zeitschrift für Säugetierkunde 60: 136-142.

Cavallini P. and Volpi T. 1996. Variation in the diet of the red fox in a Mediterranean area. Revue d'Ecologie (La Terre et la Vie) 51: 173-189.

Ginsberg J. R. and Macdonald D. W. 1990. Foxes, wolves, jackals, and dogs. An action plan for the conservation of canids. IUCN, Gland, Switzerland: 1-116.

Henry J. D. 1986. Red fox - the catlike canine. Smithsonian Institution Press, Washington, D.C.: $1-174$.

Hoffman R. A. and Kirkpatrick C. M. 1954. Red fox weights and reproduction in Tippecanoe county, Indiana. Journal of Mammalogy 35: 504-509.

LaJeunesse T. A. and Peterson R. O. 1993. Marrow and kidney fat as condition indices in gray wolves. Wildlife Society Bulletin 21: 87-90.

Lilliefors H. W. 1967. On the Kolmogorov-Smirnov test for normality with mean and variance unknown. Journal of the American Statistical Association 64: 399-402.

Lloyd H. G. 1980. The red fox. Batsford, London: 1-320.

Lund M. K. 1959. The red fox in Norway. I. Survey of 551 red foxes collected, their size and sex-ratio. Meddelelser fra Statens Viltundersokelser (Papers of the Norwegian State Game Research) 2: $1-57$.

McIntosh D. L. 1963. Reproduction and growth of the fox in the Canberra district. Wildlife Research 8: $132-141$ 
Nelson B. B. and Chapman J. A. 1982. Age determination and population characteristics of red foxes from Maryland. Zeitschrift für Säugetierkunde 47: 296-311.

Poli A., Arispici M., Marconcini A., Mancianti F. and de Monte D. 1984. Angiostrongylus vasorum (Baillet, 1866) in red foxes (Vulpes vulpes L.) in Italy. Journal of Wildlife Diseases 20: 345-346.

Wilkinson L. 1990. SYSTAT: the system for statistics. Systat Inc., Evanston, Illinois: 1-638.

Zhan Y., Yasuda J. and Too K. 1991. Reference data on the anatomy and serum biochemistry of the silver fox. Japanese Journal of Veterinary Research 39: 39-50.

Zimen E. (ed) 1980. Biogeographica Vol. 18: the red fox. W. Junk B. V. Publishers, The Hague, The Netherlands: 1-285.

Received 16 August 1996, accepted 1 February 1997. 